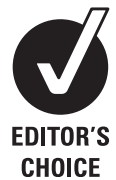

- An additional appendix is published online only. To view this file please visit the journa online (http://injuryprevention. bmj.com)

${ }^{1}$ Department of Health Policy and Management, Graduate School of Public Health, Yonsei University, Seoul, Republic of Korea

${ }^{2}$ Institute of health Services Research, Yonsei University College of Medicine, Seoul, Republic of Korea

${ }^{3}$ Department of Preventive Medicine and Public Health, Yonsei University College of Medicine, Seoul, Republic of Korea

\section{Correspondence to}

Seung-Ji Lim, Department of Health Policy and Management, Graduate School of Public Health and Institute of Health Services Research, Yonsei University, 134 Shinchon-dong, Seodaemun-gu, Seoul 120-752, Republic of Korea; sjlim@yuhs.ac; limseungji@hotmail.com

Accepted 26 March 2011 Published Online First 27 May 2011

\title{
Economic burden of injuries in South Korea
}

\author{
Seung-Ji Lim, ${ }^{1,2}$ Woo-Jin Chung, ${ }^{1,2}$ Woo-Hyun Cho ${ }^{2,3}$
}

\begin{abstract}
Background Studies on the cost of injury are useful in setting research and policy priorities and it is valuable to observe differences in the economic burden of injuries across countries.

Objective To estimate the treated prevalence rate, economic burden and gender- and age-specific costs of injuries in Korea in 2006.

Design Annual direct healthcare costs associated with injuries were estimated from the National Health Insurance, Medical Aid and Automobile Insurance databases. Annual direct non-health costs were estimated for transport and caregiver's costs. Indirect costs were estimated for premature death, absence from work and disability. Costs were adjusted to 2006 levels using the healthcare component of the Consumer Price Index.
\end{abstract}

Main outcome measures Prevalence-based direct costs, incidence-based indirect costs and total costs for injuries, stratified by gender, age group and type of injury.

Results The treated prevalence rate of injury in 2006 of the Korean population was 26.5 per 100 , resulting in an annual economic burden of \$39837 million (\$4703 million in direct and \$35 134 million in indirect costs). The cost of medical treatment associated with injuries accounted for $9.5 \%$ of the total health expenditure in Korea. The cost of premature death was the largest contributor to the total and automobile-related injuries accounted for $30.3 \%$ of total costs.

Conclusions The estimates were considerably understated because they did not include losses in household production and quality of life. Nevertheless, the size and main components of the injury burden were identified; this information should aid decision-making about research priorities and improve monitoring of the effects of policy initiatives.

\section{INTRODUCTION}

Injuries are costly to many nations. ${ }^{1}$ The largest component of the overall cost of injuries to society is that associated with productivity losses, due to premature death and long-term disability. ${ }^{2-4}$ The adequate distribution of medical resources and the establishment of proper healthcare policies are key to the effective management of this problem. ${ }^{5}$ Thus, it is important to measure the economic burden of injury from a societal perspective, using cost-of-illness (COI) studies. Such studies must estimate the resources used in disease prevention, detection and treatment, the opportunity costs of relatives providing care for patients and the foregone economic productivity associated with the inability to work, due to disability or premature death. ${ }^{5}$

Injury has been recognised as a major cause of death in Korea. It is the third leading cause of death in all age groups and the leading cause of death for those aged 1-39 years. ${ }^{6} 7$ Additionally, injury is a major disease burden, greater than that attributed to cancer and cardiovascular diseases. ${ }^{8}$ Although injury is the main cause of morbidity and mortality in Korea, no reported systematic COI study has assessed its economic burden.

The objectives of this study were to estimate the treated prevalence rate and costs of injuries that occurred in Korea in 2006 and to determine the direct and indirect costs associated with injury. Comprehensive cost estimates subdivided by multiple strata (age, gender, type of injury) show where costs might be saved or where interventions are most needed. ${ }^{9}$ Our methods will serve as a template for other countries planning a similar burden analysis and help policy makers to set priorities in injury prevention and trauma care.

\section{METHODS \\ Study design and data sources}

Prevalence-based costs are most useful for health planning and resource allocation. Incidence-based costs, however, are appropriate for analysing the savings from prevention. In this study, a prevalence approach was used for healthcare costs and an incidence approach was used for indirect costs. All resource utilisation estimates were obtained for 2006 (data are expressed in US dollars (US\$): average exchange rate, 1 US $\$=948$ Korean won; Korean Exchange Bank 2006). When costs were unavailable for 2006, the health component of the Korean Consumer Price Index was used to adjust costs to 2006 values.

Health insurance and automobile insurance (AI) are relevant to the cost of injuries in South Korea. The treated prevalence rate and cost of injuries in 2006 were estimated based on information from the administrative reimbursement claims databases of the National Health Insurance programme (NHI), the National Medical Care Aid programme (AID) and the AI programme. The Korean Medical Security system consists of the NHI and the AID. Most Koreans are beneficiaries of the NHI programme; people at the lowest income level are provided with free medical aid. Information on the medical care services associated with car-related injury treatment was provided by the AI. We were able to analyse almost every case of injury treated in Korea, except for patients receiving industrial injury compensation. In this study, the treated prevalence rate of injury was defined as the treatment episode rate for new or existing injuries of the Korean population in 2006. Information on the 2006 general population was obtained from the Korean National Statistical Office. ${ }^{10}$

We defined injuries using the International Classification of Disease, 10th version (ICD-10) 
diagnosis category S00-T98. Korean data do not include external causes of morbidity (V00-Y99).

Estimations of the COI vary between countries owing to different healthcare systems. In this analysis we included direct healthcare costs, direct non-healthcare costs and indirect costs associated with productivity losses. ${ }^{5}$ Total costs in each category were estimated by calculating the sum of the age- and genderspecific costs. The online supplementary appendix 1 shows the cost-estimation equations.

\section{Direct healthcare costs}

Information on healthcare use due to injuries in Korea included total numbers of outpatient visits and hospitalisation, the medical cost of total visits and total admissions in $2006 .^{11-13}$ Direct healthcare costs estimated from the NHI and AID omitted self-payments due to health insurance exclusions. To include these, data from a nationally representative survey of NHI patients ${ }^{14}$ were used to inflate cost estimates by the proportion of private healthcare spending, which accounted for $40 \%$ and $18.8 \%$ of inpatient and outpatient care costs, respectively. In this study, care by traditional healers and other folk-medicine providers was excluded because of a lack of data. Type of injury was defined as automobile-related injuries and other injuries.

\section{Direct non-healthcare costs}

We defined direct non-healthcare costs as costs related to patient management, excluding medical care costs. Direct non-healthcare costs related to injuries included patient travel costs and caregiver costs.

Patient travel costs were assessed as the sum of outpatient visits and admissions. Transport costs for outpatient visits were estimated by multiplying the total number of visits to outpatient clinics by the average two-way transportation cost. Costs for admissions were calculated by multiplying the total number of hospitalisations and discharges by the average two-way transportation cost. ${ }^{15}$

Caregiver costs for inpatients were calculated by multiplying the total number of inpatient days needed to treat the injury by the mean daily wages for a professional caregiver's service. ${ }^{16}$ In Korea, most inpatients were receiving care from a full-time professional caregiver or a family member during their inpatient days. For this study, we assumed that all inpatients were receiving services from a professional caregiver.

\section{Indirect costs: productivity losses}

Productivity costs were estimated as earnings lost as a result of injury-related mortality, morbidity and disability. Indirect annual costs resulting from premature death, absence from work and disability were estimated following the human capital approach, which assumes that the monetary value of lost productivity equals the wage rate. ${ }^{17}$

The present value of lost earnings due to premature mortality was calculated from data on deaths attributable to injury and data on annual earnings in 2006. Data for these calculations were obtained from the National Mortality Statistics ${ }^{10}$ and the Ministry of Labor, ${ }^{18}$ respectively. To account for different earning patterns for men and women and at different age ranges, genderand 5-year age-specific average yearly wage rates were used to estimate future earnings. The number of years of potential life lost, defined as life expectancy at the age of death, was obtained from the gender- and 5-year age-specific Korean life tables of 2006.

According to the human capital approach, only people with injury who died when aged $<65$ years of age were included in this analysis because Korean people generally retire from work after 65 and do not earn a wage. This approach was intentionally adopted to ensure that the study results were conservative.

Because productivity losses are spread across present and future years, they were adjusted to 2006 values using a 3\% discount rate. Additionally, to reflect economic growth in future earnings, the average annual economic growth rate of labour productivity between 2002 and 2006 in Korea was used.

The cost of absence from work was calculated by multiplying average daily and hourly wage rates ${ }^{18}$ by the duration of the absence from work, defined as days hospitalised and hours spent attending outpatient visits ${ }^{19}$ due to injury-related morbidity.

To calculate productivity loss due to permanent or long-term disability, we multiplied the present value of age- and genderspecific lifetime earnings losses by the probability of labour force reduction resulting from permanent disability for each type of injury. The probability of labour force reduction resulting from permanent disability was estimated by multiplying the rate of labour force separation due to disability by the probability of disability resulting from injury. ${ }^{13} 20-22$ Our estimates of the percentage of lifetime productivity potential lost due to automobile-related and other injuries were $0.28 \%$ and $0.62 \%$ per injury, respectively. Application of these estimates to our analysis assumes that these probabilities are the same for injuries that do and do not occur on-the-job and that they do not change significantly over time. We multiplied the productivity loss due to permanent or long-term disability by the number of inpatients for each type of injury.

\section{Sensitivity analysis}

To assess the robustness of cost estimates made during this analysis, sensitivity analyses were conducted. First, we evaluated the sensitivity of total injury cost estimates with respect to alternative discount rates $(5 \%$ and $7 \%$ ) of expected future earning. Second, we investigated the effect of the productivity costs associated with work loss after hospitalisation until return to work using work-loss days. To apply a monetary value to work loss, we multiplied the average daily wage by the American average of 11.1 work-loss days for each hospitalisation, as reported by Finkelstein et al. ${ }^{23}$

\section{RESULTS}

\section{Treated prevalence rate of injury in Korea}

Excluding occupational injury, the treated prevalence rate of injury in the Korean population in 2006 was 26.5 per 100 (table 1). The number of cases with treated injuries was 12952941 (7080011 in men, 5872930 in women). Of these, 11868642 cases (6398072 in men, 5470570 in women) were enrolled with the NHI and AID and 1084299 cases (681 939 in men, 402360 in women) were treated for traffic-related injuries and were enrolled with the AI. The number of injury-related deaths in 2006 was 29495 (19979 men, 9516 women).

Table 1 also shows the treated prevalence rates of injuries, according to gender and age group. Overall, the rate was $20 \%$ higher among men than women. The rate in men younger than 40 years of age was $30 \%$ higher than in women of the same age group and $68 \%$ higher when aged 10-19 years. In contrast, the rate in women older than 50 was higher than in men. The trends by gender and age group were different for automobile-related injuries. The treated prevalence rate in men was $60 \%$ higher than in women and the rate was highest among 30-49-year-olds for both genders. 
Table 1 Gender- and age-specific treated prevalence rate (per 100) of injury by insurance type in Korea, 2006

\begin{tabular}{|c|c|c|c|c|c|c|}
\hline & \multicolumn{2}{|l|}{$\mathrm{NHI+AID}$} & \multicolumn{2}{|l|}{ Al } & \multicolumn{2}{|l|}{ Total } \\
\hline & Cases & Rate & Cases & Rate & Cases & Rate \\
\hline Men & 6398072 & 26.1 & 681939 & 2.8 & 7080011 & 28.9 \\
\hline $0-9$ & 852338 & 29.3 & 24209 & 0.8 & 876547 & 30.2 \\
\hline $10-19$ & 1147832 & 32.3 & 38084 & 1.1 & 1185916 & 33.3 \\
\hline $20-29$ & 894688 & 23.0 & 134154 & 3.5 & 1028842 & 26.5 \\
\hline $30-39$ & 1050335 & 23.5 & 177177 & 4.0 & 1227512 & 27.5 \\
\hline $40-49$ & 1067108 & 24.9 & 161866 & 3.8 & 1228974 & 28.6 \\
\hline $50-59$ & 684277 & 25.3 & 96348 & 3.6 & 780625 & 28.9 \\
\hline $60-69$ & 450810 & 26.2 & 38199 & 2.2 & 489009 & 28.5 \\
\hline $70-79$ & 203448 & 26.4 & 10165 & 1.3 & 213613 & 27.7 \\
\hline $80+$ & 47236 & 23.4 & 1737 & 0.9 & 48973 & 24.3 \\
\hline Women & 5470570 & 22.4 & 402360 & 1.7 & 5872930 & 24.1 \\
\hline $0-9$ & 583382 & 21.9 & 18111 & 0.7 & 601493 & 22.6 \\
\hline $10-19$ & 603896 & 19.1 & 23916 & 0.8 & 627812 & 19.8 \\
\hline $20-29$ & 644636 & 17.5 & 81066 & 2.2 & 725702 & 19.8 \\
\hline $30-39$ & 828992 & 19.2 & 96323 & 2.2 & 925315 & 21.4 \\
\hline $40-49$ & 1004503 & 24.4 & 95981 & 2.3 & 1100484 & 26.7 \\
\hline $50-59$ & 757591 & 28.0 & 52149 & 1.9 & 809740 & 29.9 \\
\hline $60-69$ & 570053 & 28.7 & 22764 & 1.1 & 592817 & 29.9 \\
\hline $70-79$ & 356225 & 28.5 & 9771 & 0.8 & 365996 & 29.3 \\
\hline $80+$ & 121292 & 24.7 & 2279 & 0.5 & 123571 & 25.2 \\
\hline Total & 11868642 & 24.3 & 1084299 & 2.2 & 12952941 & 26.5 \\
\hline
\end{tabular}

Sources: National Health Insurance Statistical Yearbook, ${ }^{11}$ Medical Aid Statistical Yearbook, ${ }^{12}$ Analysis of motor-vehicle related injury (FY2006) from the statistical information system of Automobile Insurance. ${ }^{13}$

Al, Automobile Insurance; AID, National Medical Care Aid; Cases, treatment episodes for prevalent injuries; NHI, National Health Insurance.

\section{Cost of injuries}

Excluding occupational injury, the national economic burden of injury in 2006 was approximately $\$ 39837$ million: $\$ 4703$ million (11.8\%) for medical treatment and $\$ 35134$ million (88.2\%) for lost productivity. Of the total cost of injuries, $61.2 \%$ of the total costs was due to premature death, $21.8 \%$ due to disability, $7.6 \%$ due to direct healthcare costs, $5.2 \%$ due to absence from work, $3.2 \%$ due to caregiver's costs and $1.4 \%$ due to patient travel costs. Economic burden due to automobile-related injuries accounted for $30.3 \%$ of the overall cost (table 2 ).

\section{Gender and age differences in injury costs}

The overall cost of injuries for men was $\$ 32566$ million; this was more than 4.5 times greater than for women (\$7271 million; figure 1). Men represent $81.7 \%$ of the national economic burden of injury in Korea: $56.8 \%$ of the direct costs and $85.1 \%$ of the indirect costs. Indirect costs were the largest contributor to total injury costs for both genders. For men, premature death represented $64.2 \%$ of the overall cost of injuries, disability represented $22.8 \%$ and direct healthcare costs represented 5.3\%. For women, premature death represented $47.4 \%$ of the overall cost of injuries, direct healthcare costs represented $17.9 \%$ and disability represented $17.4 \%$.

Figure 2 shows that the distribution of the overall cost of injuries differed by age group. The proportion of direct costs increased with age, while the proportion of indirect costs decreased. For people aged 20-29, indirect costs represented $94.0 \%$ of the total cost of injuries; this decreased to $30.0 \%$ in people older than 60 .

\section{Healthcare use and costs for each episode}

Table 3 shows gender- and age-specific annual healthcare use attributed to inpatient and outpatient care due to injuries and episode-level costs for treatment cases by type of insurance. The annual length of stay for episodes treated with injuries was 20175626 days and the annual number of visits due to injuries was 46814492 . Medical care costs per episode for auto-related injuries (\$3325) were 3.3 times the costs for other non-occupational injuries (\$1000). Medical costs for each auto injury episode were much higher for children than for adults. For other injuries, the highest costs for each episode were found in elderly people and men aged $20-49$.

\section{Sensitivity analysis}

Our estimates of the total costs associated with injuries were sensitive to change in assumptions about the discount rate. Base-case COI estimates using a 3\% discount rate were \$39837 million in 2006. When estimated future earnings were discounted at $5 \%$ and $7 \%$, total injury costs were reduced to $\$ 27264$ million and \$20734 million, respectively. For work-loss costs following hospital discharge, total cost estimates were \$47577 million under the assumption of 11.1 work-loss days until return to work for each hospitalisation (table 4).

\section{DISCUSSION}

This study is the first reported attempt to estimate the national economic burden of injury by age category and gender in Korea. Many COI studies are found in Western countries, including Australia, ${ }^{24}$ Canada $^{25}$ and the USA $;{ }^{34}$ however, little is known regarding Asian countries, including Korea.

In 2006, treatment episodes with new or existing injuries were more than 12 million. This is almost 29 per 100 in men and 24 per 100 in women. Our study also showed that the costs of injury in Korea were between $\$ 20$ billion and \$39 billion in 2006 .

Table 2 Overall cost of injuries in South Korea

\begin{tabular}{|c|c|c|c|c|c|c|}
\hline \multirow[b]{2}{*}{ Type of cost } & \multicolumn{2}{|c|}{ NHI+AID } & \multicolumn{2}{|l|}{ Al } & \multicolumn{2}{|l|}{ Total } \\
\hline & Costs & $\%$ & Costs & $\%$ & Costs & $\%$ \\
\hline Direct costs & 3586 & 12.9 & 1116 & 9.2 & 4703 & 11.8 \\
\hline Direct healthcare costs & 2591 & 9.3 & 450 & 3.7 & 3041 & 7.6 \\
\hline Direct non-healthcare costs & 995 & 3.6 & 667 & 5.5 & 1662 & 4.2 \\
\hline Patient travel costs & 343 & 1.2 & 42 & 0.3 & 385 & 1.4 \\
\hline Caregiver costs & 652 & 2.4 & 625 & 5.2 & 1277 & 3.2 \\
\hline Indirect costs & 24161 & 87.1 & 10973 & 90.8 & 35134 & 88.2 \\
\hline Premature death & 15883 & 57.2 & 8484 & 70.2 & 24367 & 61.2 \\
\hline Absence from work & 1328 & 4.8 & 757 & 6.3 & 2085 & 5.2 \\
\hline Disability & 6950 & 25.0 & 1733 & 14.3 & 8683 & 21.8 \\
\hline Total costs & 27747 & 100.0 & 12090 & 100.0 & 39837 & 100.0 \\
\hline
\end{tabular}

Unit: millions of dollars (exchange rate, 1 US $\$=948$ Korean won in 2006).

Al, Automobile Insurance; AID, National Medical Care Aid; NHI, National Health Insurance. 
Figure 1 Costs for patients with injuries: men and women, 2006.
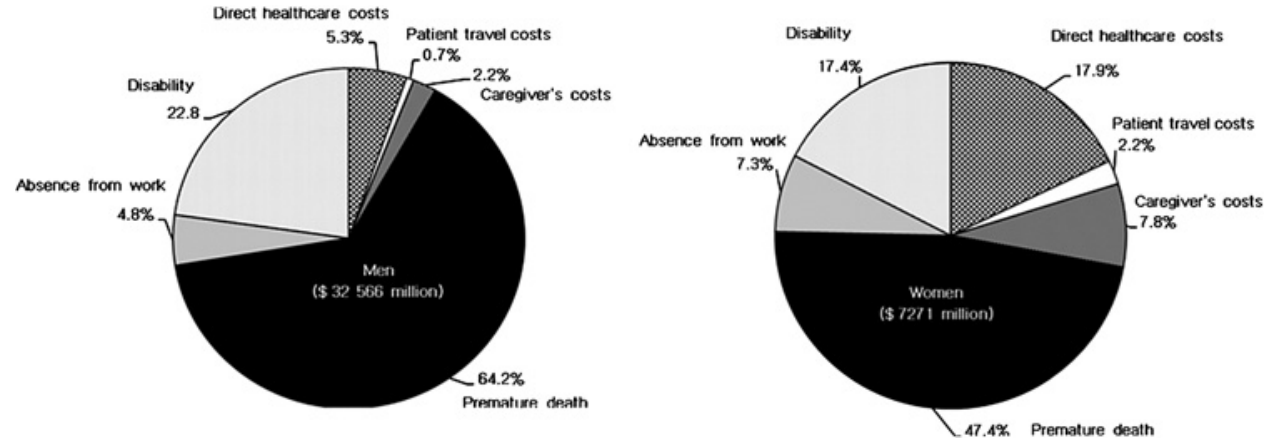

As a yardstick, this represents $2.7 \%$ and $4.9 \%$ of Korea's GDP, respectively. Also, the total costs of cancer $^{19}$ and stroke ${ }^{26}$ in Korea are $\$ 10$ billion and $\$ 6$ billion, respectively, significantly less than those of injury. This confirms that the high prevalence of injuries in Korea has a considerable public health impact and imposes a substantial economic burden on society.

We estimated total annual injury-related healthcare costs to be $\$ 3041$ million, representing $5.4 \%$ of the total health expenditure in Korea in 2006, which is $\$ 56833$ million (OECD Health Data, 2008). COI studies enable comparisons between the burdens of different diseases, aiding decision-makers in prioritising limited research funds. If such COI studies are performed at regular intervals, they can measure the impact of health policy decisions. Empirical COI studies have been published that evaluate the impact of other diseases in Korea. The healthcare costs of cancer, ${ }^{19}$ stroke, $^{26}$ and schizophrenia ${ }^{27}$ are $3.2 \%, 2.2 \%$ and $1.6 \%$ of total health expenditure, respectively, which is significantly lower than our estimates for injury. These figures indicate that the impact of injury on total health expenditure is substantial in Korea. A more systematic application of the COI approach across a wider range of diseases would provide extra information on how best to allocate research expenditures. This, however, does not mean that research priorities should be based solely on the results of COI studies.

Previous studies on injury costs have reported that the costs associated with productivity losses outweigh direct healthcare costs; productivity losses were 1.1 times higher than direct healthcare costs in Canada, ${ }^{25} 2.2$ times higher than in Australia ${ }^{24}$ and 2.4-4.0 times higher than in the USA. ${ }^{3}{ }^{4}$ According to our cost estimates, indirect costs were 7.5 times higher than direct costs. Premature death was the largest contributor to the total cost of injuries. Cross-national comparisons show premature death accounted for the largest proportion of total costs in most countries (20.6-31.3\%). ${ }^{342425}$ In this study, the cost of premature deaths due to injuries accounted for $61.2 \%$ of the total, which is higher than that reported in other countries.

The prevalence of medically treated injuries analysed in this study was almost evenly distributed between men and women. Men represent $50 \%$ of the Korean population, yet they account for $81.7 \%$ ( $\$ 32566$ million) of the total cost of injuries and $85.9 \%$ of the total years of potential life lost to injury. This cost disparity between men and women primarily results from the higher rate of fatal injuries in men and the subsequent higher productivity losses. In this study, the difference between direct and indirect costs was larger in men than in women; indirect costs were 11.1 times higher in men and 2.6 times in women. Additionally, because men, on average, receive higher wages than women, the value of lost productivity that results from a given injury is higher. Compared with a recent study in the USA, a larger difference between men and women in productivity loss was shown in this study. ${ }^{4}$ This effect may be even more pronounced in countries with a higher gender/wage gap. The
Figure 2 Distribution of overall costs for patients with injuries by age, 2006 (total $=\$ 39837$ million).

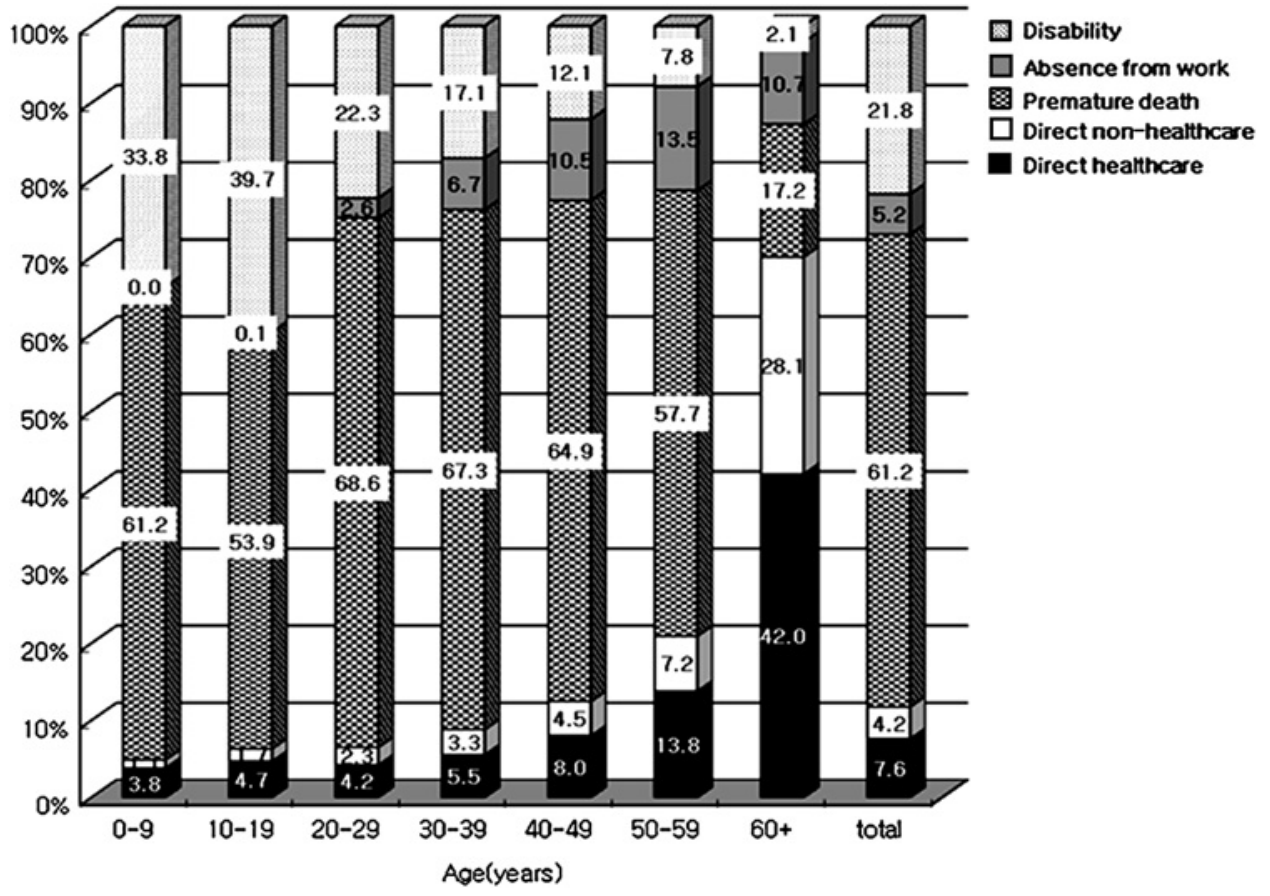


Table 3 Healthcare use and costs for each episode with injuries by gender and age groups in Korea, 2006

\begin{tabular}{|c|c|c|c|c|c|c|c|c|c|}
\hline & \multicolumn{3}{|l|}{$\mathrm{NHI}+\mathrm{AID}$} & \multicolumn{3}{|l|}{ Al } & \multicolumn{3}{|l|}{ Total } \\
\hline & LOS* & $\mathrm{NOV} \dagger$ & Costs per episode $\neq$ & LOS* & NOV $\dagger$ & Costs per episode $\neq$ & $\overline{\text { LOS }^{*}}$ & NOV $\dagger$ & Costs per episode $\neq$ \\
\hline Men & 5508490 & 22674393 & 1404 & 5709707 & 1898739 & 3909 & 11218197 & 24573132 & 4600 \\
\hline $10-19$ & 477836 & 4111386 & 1929 & 454880 & 151268 & 9228 & 932716 & 4262654 & 4626 \\
\hline $20-29$ & 719229 & 2689545 & 1753 & 1136375 & 377897 & 4504 & 1855604 & 3067442 & 6977 \\
\hline $30-39$ & 928590 & 3396583 & 1359 & 1309879 & 435595 & 3475 & 2238469 & 3832178 & 5501 \\
\hline $60-69$ & 627008 & 2033161 & 786 & 359369 & 119507 & 1900 & 986377 & 2152668 & 1424 \\
\hline $70-79$ & 391588 & 1037583 & 858 & 122386 & 40699 & 2084 & 513974 & 1078282 & 916 \\
\hline $80+$ & 150730 & 236790 & 1060 & 22941 & 7629 & 2045 & 173671 & 244419 & 1095 \\
\hline Women & 4794866 & 20350651 & 526 & 4162563 & 1890709 & 2346 & 8957429 & 22241360 & 1238 \\
\hline $0-9$ & 103957 & 1650564 & 547 & 212414 & 96482 & 4545 & 316371 & 1747046 & 1818 \\
\hline $10-19$ & 137274 & 1759213 & 462 & 327232 & 148635 & 4268 & 464506 & 1907848 & 1433 \\
\hline $60-69$ & 788500 & 2867491 & 501 & 298196 & 135446 & 1792 & 1086696 & 3002937 & 626 \\
\hline $70-79$ & 952101 & 1943523 & 942 & 139906 & 63548 & 1978 & 1092007 & 2007071 & 970 \\
\hline $80+$ & 618940 & 566549 & 1254 & 34114 & 15495 & 1841 & 653054 & 582044 & 1264 \\
\hline Total & 10303356 & 43025044 & 1000 & 9872270 & 3789448 & 3325 & 20175626 & 46814492 & 3075 \\
\hline
\end{tabular}

${ }^{*} \mathrm{LOS}=$ annual length of stay.

$+\mathrm{NOV}=$ annual number of outpatient visits

$\neq$ Costs per episode: overall costs excluding those for premature death were divided by the total number of treatment episodes for injuries to determine costs per episode in that gender and age group; costs for premature death were calculated based on data for deaths in Korea, 2006.

Unit: days, dollars (exchange rate, 1 US $\$=948$ Korean won in 2006).

Al, Automobile Insurance; AID, National Medical Care Aid; NHI, National Health Insurance.

average income of female Korean workers was $66.5 \%$ that for male workers in $2005,{ }^{28}$ compared with $77 \%$ in the USA. ${ }^{29}$ Thus, the injury burden differential between men and women is partially an artefact of wage inequality.

In this study, the cost estimation subdivided by injury type based on the type of insurance shows the impact of automobilerelated injuries. Automobile-related injuries represented $8.4 \%$ of the total, yet they accounted for 30.3\% (\$12 090 million) of the economic burden of injury. This level of cost of automobilerelated injuries was similar to that found in a previous study in the USA, ${ }^{3}{ }^{4}$ which reported that motor vehicle collisions were the most costly unintentional injury. In this study, men were $20 \%$ more likely to have an injury than women; however, men were $69 \%$ more likely to have an automobile-related injury than women. We found that the greatest economic losses attributable to automobile-related injuries were caused by the cost disparity between men and women.

Our estimates are subject to underestimation for several reasons. First, the costs included in this analysis focus exclusively on medical and productivity costs for medically treated injuries. Despite the difficulty in quantifying non-monetary outcomes, excluding these outcomes caused our total cost estimates to be substantially underestimated. In fact, a 1999

Table 4 Sensitivity analysis

\begin{tabular}{ll}
\hline Assumption & Cost (\$ millions) \\
\hline Base case & 39837 \\
Discount rate & \\
$5 \%$ & 27264 \\
$7 \%$ & 20734 \\
Work-loss days after hospitalisation & \\
11.1 days & 47577 \\
\hline Unit: millions of dollars (exchange rate, 1 US\$=948 Korean won in 2006).
\end{tabular}

study of rising worker's compensation benefits in Korea reported the implicit value of an injury to be $\$ 132445 .^{30}$ The willingnessto-pay approach needs to be studied further, incorporating the value of pain, suffering and loss of quality of life (such as disability-adjusted life years lost) with injury. ${ }^{31}$ Second, losses in household productivity due to injury were excluded from the cost estimates of productivity losses. The failure of this study to include losses in household production and quality of life may have resulted in substantial underestimation of the burden of injury on elderly people and on women and may also have resulted in serious gender and age biases. Third, to compute the cost of lost productivity, excess absence was defined as time spent for hospitalisation or ambulatory care in treating injuries. However, it generally takes time to recover normal productivity after discharge or doctor's visits. Additional research will be needed to assess the cost incurred by working individuals with injuries who return to their jobs, but with diminished productivity due to lingering disability. Fourth, we included workplace injury deaths but omitted injuries reported by workers enrolled with Industrial Injury Compensation Insurance because these data are not accessible to the public. Therefore, estimates were probably skewed by the costing of occupational deaths and the omission of non-fatal occupational injuries. Finally, we omitted the costs of police, fire department, ambulance and helicopter transport services and of insurance administration. ${ }^{3}{ }^{32}$ Another limitation is the difficulty related to interpreting the combination of prevalence-based medical costs and incidence-based and conservative work-loss costs.

Despite these limitations, the estimates reported here should be viewed as the best available estimates of injury prevalence and costs in Korea and can serve as a template for other countries carrying out a similar burden analysis; future studies with better data will improve upon the methodology and results. Our study highlights the economic burden and the public health problems 


\section{What is already known on this subject}

Injury costs associated with productivity losses outweigh direct healthcare costs.

- Premature death accounts for $20.6-31.3 \%$ of total injury costs in developed countries.

- Male subjects have higher injury incidence rates, mortality per incident and cost per injury than female subjects.

\section{What this study adds}

- The injury burden in Korea exceeded $\$ 39$ billion, significantly more than the burden of cancer or stroke.

- Medical care costs per episode for auto-related injuries were 3.3 times the costs for other non-occupational injuries.

- Medical costs per auto injury episode were much higher for children than for adults.

- Men were $20 \%$ more likely to have an injury than women and $69 \%$ more likely to have an automobile-related injury than women.

caused by injuries in Korea and provides data to help prioritise future research efforts.

Funding This study is funded by the Korea Ministry of Health, Welfare and Family Affairs.

Competing interests None.

Ethics approval This study was conducted with the approval of the institutional review board of Yonsei University Health System, Seoul, Korea.

Provenance and peer review Not commissioned; externally peer reviewed.

\section{REFERENCES}

1. Peden MM, Mcgee K, Krug E. Injury: A Leading Cause of the Burden of Disease, 2000. Geneva: World Health Organization, 2002.

2. World Health Organization. Injuruy: A Leading Cause of the Global Burden of Disease. Geneva: WHO, 2002

3. Rice DP, Mackenzie EJ. Cost of Injury in the United States: A Report to Congress. San Francisco, CA: Institute for Health \& Aging, University of California, 1989.

4. Corso $\mathbf{P}$, Finkelstein $\mathrm{E}$, Miller $\mathrm{T}$, et al. Incidence and lifetime costs of injuries in the United States. Inj Prev 2006:12:212-18.

5. Rice DP. Cost of illness studies: what is good about them? Inj Prev 2000;6:177-9.

6. Korean National Statistical Office. Annual Report on the Cause of Death Statistics (Based on Vital Registration) 2005. Seoul: KNSO, 2006.
7. Unicef. Innocenti Report Card, A League Table of Child Deaths by Injury in Rich Nations. Florence: UNICEF Innocenti Research Center, 2001.

8. Bae SC. A Study on Improvement of Health-Related Quality of Life by Measurement of Disease Burden in Korea. Seoul: Ministry for Health, Welfare and Family Affairs, 2003.

9. Polinder S, Meerding WJ, van Baar ME, et al. Cost estimation of injury-related hospital admissions in 10 European countries. J Trauma 2005;59:1283-90; discussion 90.

10. Korean National Statistical Office. Korean Statistical Information System 2007 http://kosis.kr (accessed Oct 2008).

11. Health Insurance Review Agency and National Health Insurance Corporation. 2006 National Health Insurance Statistical Yearbook. Seoul: Health Insurance Review Agency and National Health Insurance Corporation, 2007.

12. National Health Insurance Corporation. 2006 Medical Aid Statistical Yearbook. Seoul: Ministry for Health. Welfare and Family Affairs, 2007

13. Korea Insurance Development Institute. Analysis of Motor-Vehicle Accident Related Injury (FY2006): From the Statistical Information System of Automobile Insurance. Seoul: KIDI, 2007.

14. Kim CH, Lee HY, Whang LI, et al. 2006 Survey of Spending on Healthcare Among National Health Insurance Patients. Seoul: National Health Insurance Corporation, 2007.

15. Korea Center for Disease Control and Prevention. The Third Korea National Health and Nutrition Examination Survey (KNHANESIII). Seoul: KMHW, 2006.

16. Korea Care Worker Education Center. Professional Caregiver's Services, 2005. http://www.kcenet.com (accessed Oct 2008).

17. Drummond MF, O'Brien BJ, Stoddart GL, et al. Methods for the Economic Evaluation of Healthcare Programmes: Cost-Benefit Analysis. 2nd edn. New York, NY: Oxford University Press, 1997:209-12.

18. Ministry of Labor. Report on Wage Structure Survey, 2006. http://laborstat.molab. go.kr (accessed Oct 2010)

19. Chung YH, Ko SJ. Estimating socioeconomic costs of five major diseases. Korean Assoc Public Finance 2004;18:77-104.

20. Korea Institute for Health and Social Affairs. 2005 Survey Report on the Disabled. Seoul: KIHSA, 2006.

21. Korea Insurance Development Institute. 2006 Disability Status. Seoul: KIDI, 2007

22. Ministry for Health Welfare and Family Affairs. 2006 Survey on the Desabled. MIHWAF, Seoul, Korea, 2007.

23. Finkelstein E, Corso P, Miller T. The Incidence and Economic Burden of Injuries in the United States. New York, NY: Oxford University Press, 2006.

24. Watson WL, Ozanne-smith J. The Cost of Injury to Victoria. Victoria: The Department of Hyman Services, 1997.

25. Angus DE, Cloutier E, Albert T, et al. The Economic Burden of Unintentional Injury in Canada. The SMARTRISK Foundation, Ontario, Canada, 1998.

26. Lim SJ, Kim HJ, Nam CM, et al. Socioeconomic costs of stroke in Korea: estimated from the Korea National Health Insurance Claims Databases. J Prev Med Public Health 2009;42:160-4 [in Korean].

27. Chang SM, Cho SJ, Jeon HJ, et al. Economic burden of schizophrenia in South Korea. J Korean Med Sci 2008;23:167-75.

28. Korean Ministry of Gender Equality and Family. 2005 Statistical Yearbook on Gender \& Family. Seoul: Korean Ministry of Gender Equality and Family, 2005.

29. Denavas-Walt C, Proctor BD, Lee CH. Income, Poverty and Health Insurance Coverage in the United States: 2005. Washington, DC: U.S. Dept. of Commerce, Economics and Statistics Administration, US Census Bureau, 2006:60-231.

30. Kim SW, Fishback PV. The impact of institutional change on compensating wage differentials for accident risk: South Korea, 1984-1990. J Risk Uncertain 1999:18:231-48.

31. Hendrie D, Miller TR. Assessing the burden of injuries: competing measures. Inj Control Saf Promot 2004;11:193-9.

32. Miller TR, Romano EO, Spicer RS. Unintentional injuries in childhood: the cost of childhood unintentional injuries and the value of prevention. Future Child 2000;10:137-63. 